\title{
Functional Implications of Glycogen Synthase Kinase-3-Mediated Tau Phosphorylation
}

\author{
Diane P. Hanger and Wendy Noble \\ Department of Neuroscience (P037), MRC Centre for Neurodegeneration Research, King's College London, Institute of Psychiatry, \\ De Crespigny Park, London SE5 8AF, UK
}

Correspondence should be addressed to Diane P. Hanger, diane.hanger@kcl.ac.uk

Received 15 April 2011; Accepted 6 May 2011

Academic Editor: Adam Cole

Copyright (๑) 2011 D. P. Hanger and W. Noble. This is an open access article distributed under the Creative Commons Attribution License, which permits unrestricted use, distribution, and reproduction in any medium, provided the original work is properly cited.

\begin{abstract}
Tau is primarily a neuronal microtubule-associated protein that has functions related to the stabilisation of microtubules. Phosphorylation of tau is an important dynamic and regulatory element involved in the binding of tau to tubulin. Thus, highly phosphorylated tau is more likely to be present in the cytosolic compartment of neurons, whereas reduced phosphate burden allows tau to bind to and stabilise the microtubule cytoskeleton. Highly phosphorylated forms of tau are deposited in the brain in a range of neurodegenerative disorders including Alzheimer's disease, progressive supranuclear palsy, and frontotemporal lobar degeneration associated with Pick bodies. A key candidate kinase for both physiological and pathological tau phosphorylation is glycogen synthase kinase-3 (GSK-3). Multiple phosphorylation sites have been identified on tau exposed to GSK-3 in vitro and in cells. In this review, we highlight recent data suggesting a role for GSK-3 activity on physiological tau function and on tau dysfunction in neurodegenerative disease.
\end{abstract}

\section{Introduction}

The microtubule-associated protein tau is a normally soluble phosphoprotein found predominantly in neurons [1]. The structure of tau comprises three broadly defined regions, an $\mathrm{N}$-terminal projection domain, that is thought to be responsible for its interaction with membranes and other proteins, a central proline-rich domain, and a C-terminal microtubulebinding repeat region (Figure 1). Phosphorylation of tau is usually a very rapid and reversible process, which is mediated by the opposing actions of several protein kinases and phosphatases [2]. Tau phosphorylation is increased during embryonic development, and in neurodegenerative conditions, in which tau deposition is a characteristic feature $[3,4]$. Such disorders include Alzheimer's disease, progressive supranuclear palsy (PSP), and frontotemporal lobar degeneration associated with Pick bodies, amongst others, collectively termed the "tauopathies". A common factor to all of these diseases is the presence of aggregated and highly phosphorylated tau in the brain. These aggregates characteristically form intracellular inclusions comprised predominantly of tau with reduced solubility and increased reactivity to phospho-specific tau antibodies. Determining the key kinases that may be involved in the development and progression of disease pathology is an important research goal. In this review, we highlight the links between glycogen synthase kinase-3 (GSK-3) activity and tau function in normal and diseased brain.

\section{The Microtubule-Associated Protein Tau}

2.1. Tau Function and Localisation. Tau is present in the adult human central nervous system (CNS) as six isoforms that are generated from alternative splicing of a single gene. These isoforms differ from each other by the presence of none, one, or two inserts of 29 amino acids in the $\mathrm{N}$-terminus of the molecule, and the inclusion of either three (3R) or four (4R) repeated stretches of approximately 30 amino acids that comprise the microtubule-binding region of the molecule (Figure 1). Tau in embryonic brain comprises primarily the smallest $(0 \mathrm{~N} 3 \mathrm{R})$ tau isoform, and this single isoform is gradually replaced with the six adult 


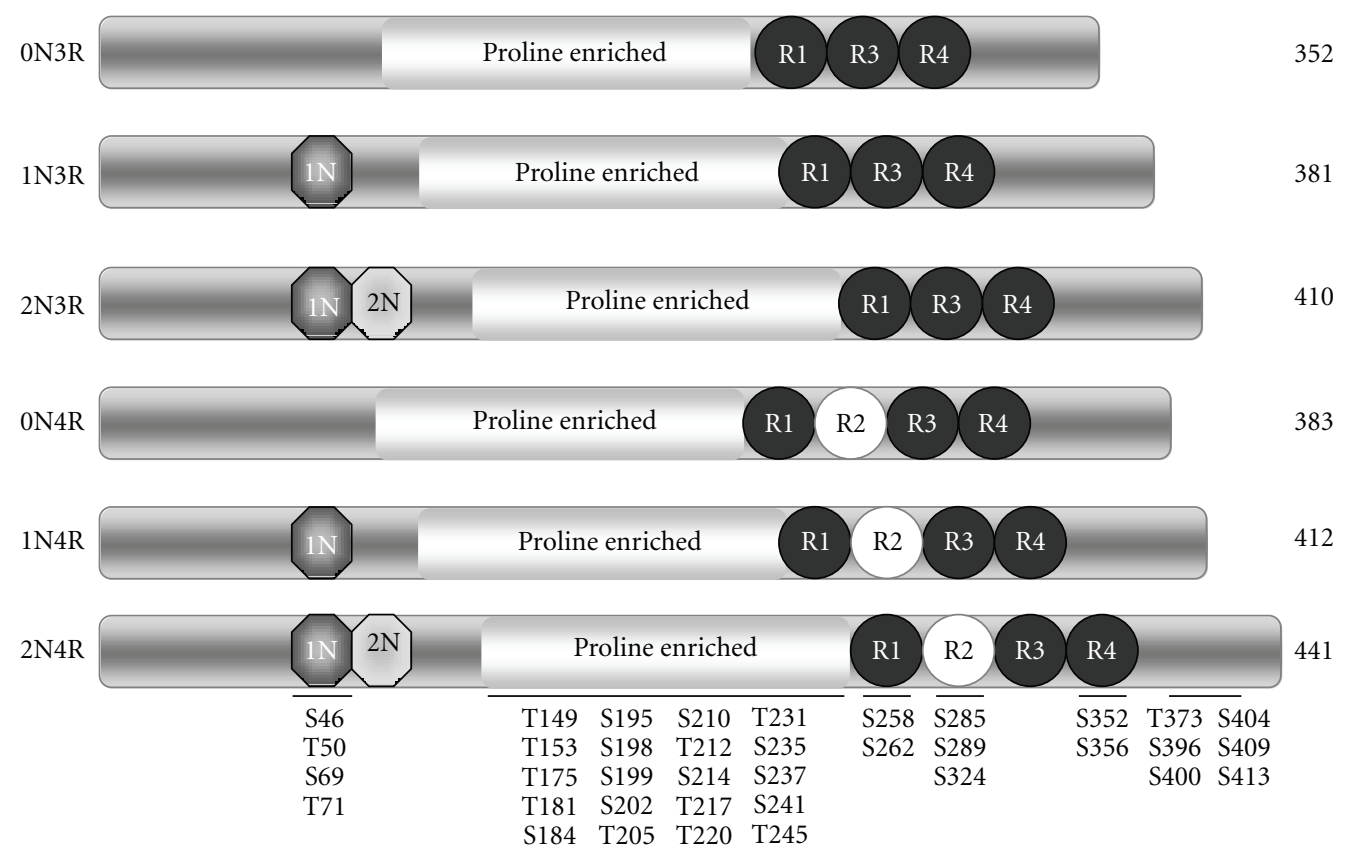

FIGURE 1: Tau isoforms in the human CNS and identified GSK-3 phosphorylation sites. The diagram illustrates the six isoforms of tau present in the human CNS. The longest tau isoform includes alternatively spliced exons 2, 3, and 10. Exons 2 and 3 encode two short amino acid inserts near the $\mathrm{N}$-terminus of the molecule $(1 \mathrm{~N}$ and $2 \mathrm{~N}$, respectively). Exclusion of exons 2 and 3 gives rise to $0 \mathrm{~N}$ tau isoforms, inclusion of exon 2 produces $1 \mathrm{~N}$ tau isoforms, and inclusion of exons 2 and 3 results in the expression of $2 \mathrm{~N}$ tau isoforms. Exon 10 encodes an additional microtubule-binding repeat domain (R2) that is present in $4 \mathrm{R}$, but absent from $3 \mathrm{R}$, tau isoforms. The number of amino acids in each tau isoform is indicated on the right. The centre of the molecule comprises a proline-enriched region that harbours the majority of the identified GSK-3 phosphorylation sites in 2N4R tau. Serine (S) and threonine (T) residues that have been identified as being phosphorylated by GSK-3 in vitro are indicated below.

isoforms during development $[5,6]$. In normal adult human brain, the ratio of the tau isoforms harbouring three or four microtubule-binding repeats is approximately equal. However, this ratio is altered in favour of expression of the $4 \mathrm{R}$ tau isoforms in several neurodegenerative tauopathies [7], although increased relative expression of $3 \mathrm{R}$ tau isoforms has also been observed in frontotemporal lobar degeneration associated with Pick bodies [8]. Thus, abnormal tau splicing and phosphorylation are both events that are closely associated with neurodegeneration.

In neurons, the primary location of tau is in axons, where it is presumed to act as a stabilising protein for the microtubule cytoskeleton. Tau has an important function in maintaining microtubule dynamic instability, through dual processes that result in the lengthening and shortening of microtubules in response to external signals [9]. Increased tau phosphorylation leads to its detachment from tubulin, thereby, enhancing microtubule disassembly and reducing microtubule stability $[10,11]$. In contrast, dephosphorylation of tau leads to an increase in its binding to tubulin, accelerated microtubule growth, and stabilisation of the microtubule cytoskeleton. Altered microtubule stability is particularly important during neurodevelopment when increased phosphorylation of tau reduces its binding to microtubules, allowing the rapid extension and retraction of exploratory neurites. Spatial and temporal changes in tau phosphorylation have been reported during neuronal differentiation
[12], and some phosphorylated epitopes on tau (e.g., PHF1, corresponding to phosphorylated Ser396/Ser404 in tau) have been associated with early stages of axon formation [13], indicating a role for tau in the development of neuronal polarity. In disease, highly phosphorylated forms of tau bind less well to microtubules, resulting in a loss of the microtubule-stabilising properties of tau and ultimately the collapse of the neuronal cytoskeleton. This has the effect of disrupting axonal transport and negatively impacting on the delivery of organelles, neurotransmitters, and other proteins to and from the cell body, with a consequent detrimental effect at synaptic termini [14-16].

Tau phosphorylation also influences the positioning of tau in dendrites, and the association of tau with plasma membranes and nuclei. Elevated phosphorylation results in the relocalisation of tau from axons into the somatodendritic region of neurons. Interactions between tau and the nonreceptor tyrosine kinase, Fyn, result in increased Fyn localisation in dendrites [17]. In models of Alzheimer's disease, increased Fyn activity in response to neurotoxic stimuli such as $\beta$-amyloid $(\mathrm{A} \beta)$, enables Fyn to phosphorylate subunit $2 \mathrm{~B}$ (NR2B) of the N-methyl-D-aspartate (NMDA) receptor, increasing the stability of this complex with the postsynaptic density (PSD) protein, PSD-95, and ultimately enhancing neurotoxicity [17]. In contrast, dephosphorylation of tau increases its association with plasma membranes $[18,19]$, which may also influence neurodegenerative processes by 
TABLE 1: Comparison of phosphorylation sites in human Alzheimer and control brain with recombinant tau phosphorylated by GSK-3 in vitro.

\begin{tabular}{|c|c|c|c|}
\hline Tau residue number & Alzheimer tau & Control brain tau & GSK-3 \\
\hline Tyr18 & A & & \\
\hline Ser46 & A & $\bullet$ & • \\
\hline Thr50 & & & • \\
\hline Ser68 & $\bullet$ & & \\
\hline Thr69 & - & & - \\
\hline Thr71 & • & & \\
\hline Ser113 & $\bullet$ & & \\
\hline Thr123 & A & & \\
\hline \multicolumn{4}{|l|}{ Ser131 } \\
\hline Thr149 & & & - \\
\hline Thr153 & A & & • \\
\hline Thr175 & - & & - \\
\hline Thr181 & - & $\bullet$ & - \\
\hline Ser184 & - & & - \\
\hline Ser185 & - & & \\
\hline Ser191 & - & & \\
\hline Ser195 & & & - \\
\hline Tyr197 & - & & \\
\hline Ser198 & $\bullet$ & • & - \\
\hline Ser199 & - & • & - \\
\hline Ser202 & $\bullet$ & • & - \\
\hline Thr205 & A & • & • \\
\hline Ser208 & $\bullet$ & & \\
\hline Ser210 & • & & - \\
\hline Thr212 & - & - & - \\
\hline Ser214 & - & & - \\
\hline Thr217 & - & - & - \\
\hline Thr220 & & & - \\
\hline Thr231 & $\bullet$ & $\bullet$ & - \\
\hline Ser235 & - & - & - \\
\hline Ser237 & - & & - \\
\hline Ser238 & - & & \\
\hline Ser241 & & & - \\
\hline Thr245 & & & - \\
\hline Ser258 & • & & - \\
\hline Ser262 & - & & - \\
\hline Ser285 & & & • \\
\hline Ser289 & - & & - \\
\hline Ser305 & & & • \\
\hline Ser324 & & & - \\
\hline Ser352 & & & • \\
\hline Ser356 & • & & - \\
\hline Thr373 & & & • \\
\hline Tyr394 & • & & \\
\hline Ser396 & • & • & • \\
\hline Ser400 & • & • & • \\
\hline Thr403 & • & & \\
\hline Ser404 & $\bullet$ & $\bullet$ & $\bullet$ \\
\hline
\end{tabular}

TABLE 1: Continued.

\begin{tabular}{lccc}
\hline Tau residue number & Alzheimer tau & Control brain tau & GSK-3 \\
\hline Ser409 & $\bullet$ & $* *$ & $\bullet$ \\
Ser412 & $\bullet$ & $* *$ & \\
Ser413 & $\bullet$ & $* *$ & \\
Thr414 & $*$ & $\bullet$ & \\
Ser416 & A* & \\
Ser422 & $\bullet$ & & \\
Thr427 & $\bullet$ & & \\
Ser433 & $\bullet$ & & \\
Ser435 & $\bullet$ & & \\
\hline
\end{tabular}

Numbering of residues refers to $2 \mathrm{~N} 4 \mathrm{R}$ human tau, the largest isoform present in the human CNS.

- indicates tau phosphorylation sites identified by direct means.

A indicates tau phosphorylation sites identified using phospho-specific tau antibodies.

* indicates that one of the two closely spaced phosphorylation sites indicated (Thr414, Ser416) is phosphorylated in tau from AD brain.

** indicates that two of the three closely spaced phosphorylation sites indicated (Ser412, Ser413, Thr414) are phosphorylated in tau from control human brain.

mediating the interactions of tau with membrane-associated cell-signalling molecules such as Src-family kinases and phospholipase C- $\gamma$ [20-22].

A pool of tau has also been identified in the nucleus of cultured cells and in brain tissue [23-28]. In human neuroblastoma cells, tau has been identified in the nucleolar organiser region [23], and, thus, tau-DNA binding may be involved in nucleolar organisation [27]. It has been reported that the phosphorylation of tau, particularly in response to heat stress, increases the amount of tau found in neuronal nuclei [29], although this finding is somewhat controversial [30]. The microtubule-binding domain of tau associates with RNA [31] and DNA [32], and the association of nuclear tau with DNA in response to stress is believed to play a role in protecting DNA from damage [29]. Tau has been found to be associated with the, predominantly nuclear protein, mammalian solute transport protein-2 (SUT2). SUT2 is localised to SC35-positive speckles in the nucleus, and it may have a role in mRNA processing [33]. Expression of this protein in C. elegans potentiates tau neurotoxicity [34, 35]. In addition, mammalian SUT2 is reduced in diseaseaffected regions of Alzheimer brain, under conditions where tau phosphorylation is increased, and SUT2 expression is increased when tau is overexpressed in mammalian cells in culture [34]. RNAi knockdown of SUT2 in cultured human cells overexpressing tau results in a marked decrease in tau aggregation, with no apparent effect on soluble tau species, suggesting a possible role for SUT2 in the pathogenesis of tauopathies [34]. Thus, tau may mediate neurodegeneration by changes in phosphorylation that result in both losses and gains of tau function.

2.2. Tau Phosphorylation. Tau possesses 80 phosphorylatable serine and threonine residues, approximately $20 \%$ of which have been identified as being phosphorylated in normal human brain (Table 1). A further five tyrosine residues in 
tau are also amenable to phosphorylation by tyrosine kinases, including Fyn, Syk, c-Abl, and Lck $[36,37]$. A large number of serine/threonine kinases have been reported to phosphorylate tau in vitro, but the identity of the protein kinase(s) responsible for regulating physiological tau phosphorylation remains unknown [7]. Candidate serine/threonine-directed tau kinases include GSK-3, casein kinase 1 (CK1), and cyclindependent kinase-5 (cdk5), amongst others [7]. It seems likely that more than one kinase may be involved in the phosphorylation of tau. However, substantial evidence exists to support a major role for GSK-3 in both physiological and pathological tau phosphorylation.

\section{Glycogen Synthase Kinase-3}

3.1. GSK-3 Isoforms. GSK-3 exists as two isoforms, $\alpha$ and $\beta$, which share $85 \%$ sequence identity and are encoded by distinct genes located on chromosomes 19 and 3, respectively [38]. GSK-3 $\alpha$ and GSK-3 $\beta$ both phosphorylate tau in vitro and appear as granules with slightly differing morphologies and densities in pyramidal cells of hippocampal neurons [39]. There are two variants of GSK-3 $\beta$, with GSK-3 $\beta 2$ differing from GSK-3 $\beta 1$ by the presence of an additional insertion of 13 amino acids. GSK-3 $\beta 2$ is enriched in neurons, where it is present in cell bodies, neuritis, and growth cones [40]. GSK- $3 \alpha$ and GSK-3 $\beta$ share many substrates and appear to be able to compensate partially for each other, although they also appear to have distinct functions [41]. A recent report has shown that, whereas GSK-3 $\beta$ is present in birds, GSK $-3 \alpha$ is absent, indicating that the GSK-3 $\alpha$ isoform is not required either for viability or for normal physiological function in birds [42]. Furthermore, knockout of GSK-3 $\alpha$ in mice results in increased insulin sensitivity [43], suggesting a role for GSK-3 $\alpha$ in glucose metabolism that cannot be replaced by GSK-3 $\beta$. In contrast, complete knockout of GSK$3 \beta$ in mice is embryonic lethal [44].

3.2. Regulation of GSK-3 Activity. The kinase activity of GSK-3 is regulated by its phosphorylation at serine and tyrosine residues. Phosphorylation of GSK-3 $\alpha / \beta$ at Tyr216 and Tyr279 is believed to maintain the constitutive activity of GSK-3 in neurons (reviewed in [45]), while the phosphorylation of Ser 21 on GSK- $3 \alpha$ or Ser9 on GSK-3 $\beta$ negatively regulates GSK-3 activity [45], and phosphorylation at these residues is believed to the predominant mediator of GSK-3 activity in vivo [46]. Both protein phosphatase 1, (PP1) and PP2A are known to target Ser21/9 and thus regulate GSK-3 activity [47]. Indeed, PP activation with okadaic acid leads to increased phosphorylation of S9 and, hence, inhibition of GSK-3 $\beta$, which results in reduced tau phosphorylation [48]. Other phosphatases could also be involved in GSK-3 regulation since calcineurin (PP2B) also dephosphorylates and hence activates GSK-3 [49]. In addition, one of the many substrates of GSK-3 is the inhibitory subunit (inhibitor-2) of PP1. The phosphorylation of this subunit leads to its activation which results in the inhibition of PP1 [50], and decreased GSK-3 activity, demonstrating one mechanism through which GSK-3 activity may be regulated.
3.3. GSK-3 Regulation of Tau Splicing. In addition to phosphorylating tau, GSK-3 can influence tau splicing. GSK-3 has been shown to phosphorylate nuclear SC35, an enhancer of splicing elements that regulate exon 10 splicing in tau $[51,52]$. A $\beta$ application to cultured cells activates GSK-3 [53], leading to the phosphorylation of SC35 in parallel with enhanced splicing of tau exon 10 and decreased expression of $4 \mathrm{R}$ tau [54]. These events can be suppressed by the inhibition of GSK-3 activity with lithium or following siRNA knockdown of GSK-3 [54]. Despite these findings, most research investigating GSK-3 regulation of tau function has concentrated on GSK-3-mediated phosphorylation of tau.

3.4. GSK-3 Regulation of Tau Phosphorylation. Tau is a good substrate for GSK-3 in vitro $[39,55]$, in cultured nonneuronal cells [56], and in transgenic mice overexpressing GSK-3 [57]. In brain, tau exists in a complex with GSK-3 and the scaffolding protein 14-3-3 [58]. 143-3 recognises GSK-3 phosphorylated at Ser9, and indeed GSK-3 in this complex is phosphorylated at Ser9 in brain $[58,59]$. The association of tau with this complex is believed to regulate its phosphorylation by GSK-3, since in human embryonic kidney cells, tau phosphorylation by GSK-3 is suppressed in the absence of 14-3-3, but GSK-3 is active and phosphorylates tau if $14-3-3$ is present [59].

\section{In vitro Phosphorylation of Tau by GSK-3}

Tau is phosphorylated by GSK-3 on approximately 40 different serine and threonine residues, at least in vitro $[60,61]$. The importance of this finding should not be underestimated since few kinases have been shown to target this number of sites in tau. Indeed, CK1 is the only other kinase that has been reported to phosphorylate a similar number of tau residues. Treatment of primary neuronal cortical cultures with specific inhibitors of either GSK-3 or CK1 reduces tau phosphorylation, suggesting that these kinases could have functionally important roles in neurons $[7,14,60]$. The phosphorylation of tau by GSK-3 or CK1 also reduces the ability of tau to promote microtubule assembly in vitro and in cells $[62,63]$. These results rank GSK-3 and CK1 as targeting the greatest number of phosphorylatable residues on tau and implicate these two protein kinases in physiological tau phosphorylation in neurons. It remains to be seen whether the activities of GSK-3 and/or CK1 are modified in diseases in which increased phosphorylation of tau is a characteristic feature.

4.1. Potential Priming of Tau for GSK-3 Phosphorylation. It is well established that GSK-3 preferentially phosphorylates many of its substrates after they have been prephosphorylated by other kinases, and this seems also to be true for tau phosphorylation by GSK-3. Other examples of GSK-3 substrates that require prephosphorylation by another kinase before recognition by GSK-3 include glycogen synthase, inhibitor- 2 of PP1, the regulatory subunit of cyclic AMP-dependent protein kinase (PKA), cAMP response element-binding (CREB), $\beta$-catenin, and kinesin light chain $[46,64]$. Most priming phosphorylations for GSK-3 occur at 
an amino acid located four residues C-terminal to the target residue [65]. However, there are some exceptions to this rule, and priming events have been reported that occur five or six residues from the GSK-3 target site, for example, in collapsin response mediator protein-2 and also in tau $[66,67]$. The GSK-3 priming phosphorylation is frequently provided by the activity of PKA, CK1, or CK2 on unphosphorylated substrates, although other kinases, such as members of the mitogen-activated protein kinase family, or cdk5, can also initiate priming on some GSK-3 substrates $[68,69]$. As has previously been shown, CK1 primes $\beta$-catenin for subsequent phosphorylation by GSK-3 (reviewed in [69]), and this might also occur on tau because the rate of GSK-3 phosphorylation of tau is increased when it is first phosphorylated by CK1 [70]. Substrate priming, therefore, may represent an important regulatory element of GSK-3 signalling since the activity of GSK-3 has been reported to differ for its primed and nonprimed substrates [68]. In the case of tau, this is supported by the observation that targeting GSK-3 phosphorylation of tau to either unprimed or primed sites has a differential impact on the binding of tau to microtubules $[71,72]$.

There are 24 short sequences of amino acids in tau that conform to the strict consensus sequence Ser/Thr-XXXSer/Thr (indicating pairs of serine or threonine residues separated by any three amino acids), that could be implicated in priming for GSK-3. Fourteen of these serine/threonine pairs have been found to be phosphorylated in vitro by GSK-3 (Table 1), and six pairs contain a proline residue immediately C-terminal to the target sequence. Five of the 10 remaining paired amino acids are phosphorylated by GSK-3 on only one of the two serine or threonine residues and five pairs have not been shown to be phosphorylated by GSK-3. Relaxation of the consensus sequence to include a separation of five or six amino acids between potential priming sites would allow the inclusion of further sets of amino acids, including Ser214, Ser210, Thr205, and Ser199 (see below). Overall, therefore, tau appears to fulfil several of the requirements for GSK-3 substrates, including multiple Ser/Thr-Pro sequences with nearby N-terminal phosphorylatable amino acids closely opposed, which could allow for kinase priming, either by GSK-3 itself or by other tau kinases.

Priming phosphorylation on tau residues Ser235 and Ser404 by other kinases, including cdk5, has been shown to promote phosphorylation by GSK-3 at Thr231 and Ser400, respectively $[71,72]$. Interestingly, the stretch of amino acids in tau that includes the phosphorylatable residues, Ser396, Ser400, and Ser404, can be directly phosphorylated by GSK3 without the prior activity of other kinases [67]. However, phosphorylation at Ser404 is critical to this process and substitution of this residue by alanine ablates phosphorylation of both Ser396 and Ser400. It appears, therefore, that the primary phosphorylation of Ser404 by GSK-3 can itself serve as a primed residue for the subsequent sequential phosphorylation of tau at Ser400 and Ser396 by GSK-3. However, the functional significance of many of the other potential GSK-3 priming sites in tau has not been widely investigated.
Prephosphorylation of tau by PKA for subsequent GSK3 phosphorylation in rat brain appears to particularly enhance the overall amount of GSK-3 phosphorylation [73]. Furthermore, the initial phosphorylation of tau by PKA results in a different spectrum of phosphorylation sites generated by the action of GSK-3 compared to those produced when tau is exposed to GSK-3 alone, demonstrating that prior phosphorylation by PKA alters the recognition of tau by GSK-3 [73]. Moreover, initial phosphorylation of tau by PKA, which occurs primarily on Ser214, results in the subsequent phosphorylation by GSK-3 of four closely spaced residues, namely Ser210, Thr205, Ser199, and Ser195, each separated by 4-6 amino acids [67]. Interestingly, this study also revealed an interaction between the low-density lipoprotein receptor-binding domain of apolipoprotein $\mathrm{E}$ (ApoE), a major genetic risk factor for Alzheimer's disease, and GSK-3-phosphorylated tau [67]. Such an interaction was not observed with either nonphosphorylated tau or following extensive phosphorylation of tau by PKA. These results suggest that the pattern of phosphorylation sites generated by the action of GSK-3 on tau may be critical for its interaction with ApoE.

4.2. GSK-3 $\alpha$ and GSK-3ß1/2 Isoforms Differentially Phosphorylate Tau. Suppressing the expression of individual GSK$3 \alpha$ and GSK-3 $\beta$ isoforms results in differing tau phosphorylation patterns [74]. The induction of a phosphorylationinduced shift in electrophoretic mobility of tau, following incubation with GSK-3, also appears to be favoured preferentially by GSK-3 $\beta$, rather than GSK- $3 \alpha$, as is tau phosphorylation at the antibody epitopes recognised by tau1 (Ser199-Ser202) and 8D8 (Ser396) [39]. Together, these results support the view that GSK-3 $\alpha$ and GSK-3 $\beta$ are likely to have differing preferences for tau that may be related to the distinct, but overlapping, intracellular locations of these kinases in neurons.

There is also a difference in the kinetics and sites of tau phosphorylation induced by the two GSK-3 $\beta$ isoforms, with GSK-3 $\beta 2$ appearing to phosphorylate tau more slowly than GSK-3 $\beta 1$ and on different, with some overlapping, tau residues, even under conditions in which other GSK$3 \beta$ substrates, such as amyloid precursor protein, are phosphorylated equally $[75,76]$. For example, Ser396 in tau is phosphorylated by both splice variants, whereas Ser199 is a significant target of GSK- $3 \beta 1$, but not of GSK-3 $\beta 2$ activity. It has recently been suggested that the interaction of GSK-3 $\beta 2$ with tau is weaker than that of GSK-3 $\beta 1$ [76]. Taken together, these results suggest that, not only are there differential activities of GSK- $3 \alpha$ and GSK-3 $\beta$ towards tau, there are also partially overlapping, but distinct, tau phosphorylation sites recognised by each of the two isoforms of GSK-3 $\beta$ [74-77].

\section{Tau Phosphorylation in Human Brain}

In the tauopathies, tau is present in both normally phosphorylated and highly phosphorylated forms, the latter of which may be potentially pathological since it is most commonly observed as intraneuronal aggregates or glial inclusions. 
Tau is normally a highly soluble protein under nondenaturing conditions, but the aggregated tau present in diseased brain displays a significantly reduced solubility and an increased reactivity to phospho-specific tau antibodies [78]. These characteristic features have facilitated purification strategies for tau from diseased brain exhibiting tau pathology which yield relatively enriched preparations of highly phosphorylated tau. Such preparations have resulted in the identification of phosphorylation sites on insoluble tau isolated from human tauopathy brain, thereby providing clues to the identities of protein kinases that are potentially involved in the pathogenesis or development of these neurodegenerative diseases [60,79-81].

In particular, these approaches have been used to identify phosphorylation sites on purified tau from Alzheimer's disease and PSP brain material, as well as soluble tau from control adult and foetal brain $[60,82,83]$. These studies, combined with results obtained from immuno-labelling with phospho-specific tau antibodies, have led to the identification of approximately 45 phosphorylation sites on tau from Alzheimer brain (Table 1). In comparison, only 15 phosphorylation sites have been detected in insoluble tau from PSP brain and 16 sites on control brain tau, not all of which overlap, and for some of which no kinase has yet been identified [7].

A comparison of tau extracted from human brain with tau phosphorylated using protein kinases in vitro shows that GSK-3 remains a principal candidate kinase for both physiological and pathological tau phosphorylation (Table 1). Although GSK-3 has been reported to be associated with neurofibrillary pathology in Alzheimer's disease and related neurodegenerative disorders $[84,85]$, other studies have not identified such colocalisation $[39,86]$, and it remains to be seen if GSK-3 remains associated with tau pathology in diseased brain. In the case of tau extracted from neurologically normal human brain, all but two residues have been shown to be phosphorylated by GSK-3. These two sites, Ser412 and Thr414, are located within a group of three closely spaced residues, including Ser413, of which only two residues are phosphorylated in human brain. Since GSK3 phosphorylates Ser413, it is possible that only a single site, either Ser412 or Thr414, remains unphosphorylated by GSK-3, and, of these, Ser412 is phosphorylated by both CK1 and PKA, and potentially also by CK2. This suggests that, under physiological conditions, tau in human brain may be phosphorylated primarily by GSK-3, with potential contributions from CK1, CK2, or PKA. Under pathological conditions such as Alzheimer's disease, in which tau becomes deposited in the brain, GSK-3 accounts for some 27 of the approximately 45 tau phosphorylation sites identified in insoluble tau. The remaining phosphorylation sites are accounted for the activities of a combination of other kinases, including the tyrosine kinases, c-Abl, and Fyn, although there remain a few sites for which a kinase has not yet been identified. Thus GSK-3 plays a prominent role in both the physiological and pathological phosphorylation of tau in human brain.

\section{Cellular Models of Tau Phosphorylation by GSK-3}

Further information regarding the role of GSK-3 in tau phosphorylation and function has been gained from cell models. In cells, the involvement of GSK-3 was first revealed when GSK-3 over-expression was shown to disrupt tau binding to microtubules, resulting in a diffuse cytoplasmic localisation of tau [56]. This staining pattern contrasts with the strongly fibrillar pattern displayed when tau is expressed alone. Cellular phosphorylation of tau by GSK- $3 \beta$ overexpressed in mammalian cells decreases tau binding to microtubules and influences microtubule organisation [87, 88]. This process is inhibited by mouse dishevelled-1, thereby potentially implicating the wingless signalling pathway in tau phosphorylation mediated by GSK-3 [89].

Investigations in human neuronal NT2N cells have shown that tau phosphorylation at multiple sites recognised by phospho-specific tau antibodies could be prevented by lithium treatment, which inhibits GSK-3 activity [90]. Lithium also promotes tau binding to microtubules and subsequent microtubule polymerisation, suggesting a role for GSK-3 in this normal physiological process [90]. It is important to note that lithium is not a specific inhibitor of GSK3 as it also effectively inhibits inositol monophosphatase, as well as a family of structurally related phosphomonoesterases (reviewed in [91]). However, the reported effects of lithium on tau phosphorylation in cells have subsequently been validated in studies using more selective GSK-3 inhibitors $[74,92,93]$. The examination of endogenous tau phosphorylation by GSK-3 in primary rat neurons has revealed a number of lithium-sensitive sites, suggesting that these might represent the physiological targets of GSK-3 on tau [14, 94]. Interestingly, in the latter study, the inhibition of GSK-3, either by lithium or by the more specific GSK-3 inhibitor, SB-415286, resulted not only in reduced tau phosphorylation but also in reduced axonal transport of tau [14]. This led to the idea that tau phosphorylation mediated by GSK-3 could influence tau axonal transport, at least in primary neuronal cultures [14]. In an ex vivo study, perfusion of preformed filaments of tau into isolated squid axoplasm resulted in the inhibition of anterograde transport of membrane-bound organelles [95]. Interestingly, inhibiting GSK-3 activity, or perfusion of inhibitor- 2 to inhibit PP1 activity, overcame the detrimental effect of tau filaments on axonal transport in this model [95]. These results, thus, support the notion that GSK-3 has an important role in relation to tau function in neurons.

Inhibiting GSK-3 with SB-415286 also protects cultured neurons from cell death induced by reduced phosphatidylinositol 3-kinase activity, and this protection is paralleled by decreased tau phosphorylation [92]. These results suggest that the state of tau phosphorylation by GSK-3 in cells is important for the maintenance of healthy functional neurons, and changes in tau phosphorylation are likely be indicative of reduced neuronal viability. 


\section{Animal Models of Tau Phosphorylation by GSK-3}

7.1. Drosophila. Over-expression of tau together with GSK3 (the human orthologue of shaggy/Zw3 in Drosophila) has been demonstrated to exacerbate the neurodegeneration resulting from expression of tau alone in Drosophila melanogaster [96], suggesting that the phosphorylation of tau by GSK-3 is involved in the neurodegenerative process. The presence of partition-defective 1 (PAR-1), the Drosophila orthologue of mammalian microtubule affinity regulating kinase (MARK), has been shown to be required to initiate GSK-3 and cdk5 phosphorylation of tau in flies [97]. However, reports differ as to whether PAR1 activity enhances $[97,98]$ or suppresses $[15,99,100]$ tau-induced toxicity, although PAR-1 over expression in Drosophila appears to increase neuronal loss [97]. MARK phosphorylates tau on Ser262 and Ser356 in vitro, both of which are located within the microtubule-binding domain of tau, and this phosphorylation results in the disruption of microtubules [101]. MARK phosphorylation, therefore, results in the detachment of tau from microtubules, and this may be related to its involvement in microtubule-based axonal transport in neurons [102]. Interestingly, MARK itself is phosphorylated by GSK-3, resulting in MARK inactivation [103], suggesting the possible involvement of multiple tau kinases in this model, however the relevance GSK-3 and MARK interaction to tau phosphorylation has not yet been determined.

More recent studies have found that tau phosphorylation in Drosophila is not dependent on GSK-3 activity. A mutant form of tau, described as GSK-3 resistant, retained toxicity in flies, and, under these conditions, mutant tau exhibited an increased affinity for binding to microtubules [98]. Notably, while GSK-3 phosphorylation of tau was impaired in these flies, toxicity was unaffected, suggesting that the ability of tau to bind to microtubules, or possibly the propensity of GSK-3 to alter the oligomerisation state of tau, may be critical for neurodegeneration.

Drosophila express a form of tau with limited homology to human tau, especially in the microtubule-binding region [104]. There is less than 50\% amino acid identity between the presumed microtubule-binding domain of Drosophila and mammalian tau. Coupled with the presence of an additional microtubule-binding repeat in flies, these considerable differences between invertebrate and mammalian tau suggest that the results obtained by overexpressing GSK-3 in flies may differ from those obtained in the presence of human tau. The relationship, therefore, between tau toxicity and tau phosphorylation in Drosophila warrants further investigation if it is to be applied to study the physiological relevance of GSK-3 phosphorylation of tau.

7.2. Mice. The influence of GSK-3-mediated tau phosphorylation in mammals has been studied in various mouse models (reviewed in [105]). The postnatal over-expression of GSK-3 in mice results in GSK-3 activation and the development of several characteristics of human tauopathy including elevated tau phosphorylation, reactive gliosis, spatial learning deficits, and neuronal death [106, 107]. These features can be reversed by suppressing GSK-3 $\beta$ expression [108], indicating that tau is a prime substrate for GSK-3 in vivo. Indeed, the axonopathy and motor impairment resulting from over-expression of human $2 \mathrm{~N} 4 \mathrm{R}$ tau in mice is alleviated when GSK-3 $\beta$ is coexpressed [109], with this beneficial effect believed to occur as a result of GSK3 phosphorylation of tau removing excess tau from microtubules. Further support for a potential pathological role of GSK-3-phosphorylated tau has come from studies showing that GSK-3 inhibition in transgenic mice expressing diseaseassociated mutant human tau reduces tau phosphorylation and aggregation [110-114] as well as axonal degeneration [111].

\section{Conclusions}

Changes in the phosphorylation state of tau have a major impact on its subcellular localisation and function in neurons. Major changes in the phosphorylation state of tau are evident under two apparently unrelated conditions, that is, during early neuronal development and during neurodegenerative processes that lead to the deposition of highly phosphorylated pathological tau in the brain, such as in Alzheimer's disease. Therefore, determining the nature of the kinases involved in this process in vivo is an important research goal that will improve our understanding of these processes.

GSK-3 is a key candidate kinase for tau phosphorylation, under both physiological and pathological conditions. Multiple serine and threonine residues on tau are targeted by GSK3 in vitro, with many of these sites being coincident with those phosphorylated in vivo. Together with the, possibly coordinated, activity of other kinases, including CK1, cdk5, PKA and/or MARK, GSK-3 is well positioned to act on tau in such a way that will result in significant and rapid tau phosphorylation and, hence, modulation of its function in neurons. Understanding the regulation of GSK-3 activity in neurons, including the possible differential effects of the related GSK-3 $\alpha$, GSK-3 $\beta 1$, and GSK-3 $\beta 2$ isoforms, should lead to further elucidation of the mechanisms underlying tau phosphorylation and may ultimately lead to new therapeutic targets for neurodegenerative disease.

\section{Abbreviations}

$\mathrm{A} \beta$ : $\quad \beta$-amyloid

ApoE: Apolipoprotein E

cdk5: Cyclin-dependent kinase-5

CK: $\quad$ Casein kinase

CNS: Central nervous system

CREB: Cyclic AMP response element binding

GSK-3: Glycogen synthase kinase-3

MARK: Microtubule-affinity regulating kinase

NMDAR: N-methyl-D-aspartate receptor

NR2B: Subunit 2B of the NMDA receptor

PAR-1: Partition-defective 1

PKA: Cyclic AMP-dependent protein kinase

PP: $\quad$ Protein phosphatase 
PP2B: Calcineurin

PSD: Postsynaptic density

PSP: Progressive supranuclear palsy

Ser: Serine

SUT2: Solute transport protein-2

Thr: Threonine

Tyr: Tyrosine.

\section{Acknowledgments}

Work in the authors' laboratories is funded by the UK Medical Research Council, The Wellcome Trust, Alzheimer's Research UK, The Henry Smith Charity, and The Royal Society.

\section{References}

[1] M. Goedert, "Tau protein and the neurofibrillary pathology of Alzheimer's disease," Trends in Neurosciences, vol. 16, no. 11, pp. 460-465, 1993.

[2] L. Buée, T. Bussière, V. Buee-Scherrer, A. Delacourte, and P. R. Hof, "Tau protein isoforms, phosphorylation and role in neurodegenerative disorders," Brain Research Reviews, vol. 33, no. 1, pp. 95-130, 2000.

[3] C. Ballatore, V. M. Lee, and J. Q. Trojanowski, "Taumediated neurodegeneration in Alzheimer's disease and related disorders," Nature Reviews Neuroscience, vol. 8, no. 9, pp. 663-672, 2007.

[4] T. F. Gendron and L. Petrucelli, "The role of tau in neurodegeneration," Molecular Neurodegeneration, vol. 4, p. 13, 2009.

[5] C. Viereck, R. P. Tucker, and A. Matus, "The adult rat olfactory system expresses microtubule-associated proteins found in the developing brain," Journal of Neuroscience, vol. 9, no. 10, pp. 3547-3557, 1989.

[6] R. P. Tucker, "The roles of microtubule-associated proteins in brain morphogenesis: a review," Brain Research Reviews, vol. 15, no. 2, pp. 101-120, 1990.

[7] D. P. Hanger, B. H. Anderton, and W. Noble, "Tau phosphorylation: the therapeutic challenge for neurodegenerative disease," Trends in Molecular Medicine, vol. 15, no. 3, pp. 112119, 2009.

[8] M. Hasegawa, "Biochemistry and molecular biology of tauopathies," Neuropathology, vol. 26, no. 5, pp. 484-490, 2006.

[9] T. Mitchinson and M. Kirschner, "Dynamic instability of microtubule growth," Nature, vol. 312, no. 5991, pp. 237242, 1984.

[10] G. Lindwall and R. D. Cole, "Phosphorylation affects the ability of tau protein to promote microtubule assembly," Journal of Biological Chemistry, vol. 259, no. 8, pp. 53015305, 1984.

[11] D. N. Drechsel, A. A. Hyman, M. H. Cobb, and M. W. Kirschner, "Modulation of the dynamic instability of tubulin assembly by the microtubule-associated protein tau," Molecular Biology of the Cell, vol. 3, no. 10, pp. 1141-1154, 1992.

[12] C. K. Combs, P. D. Coleman, and M. K. O’Banion, "Developmental regulation and PKC dependence of Alzheimer'stype tau phosphorylations in cultured fetal rat hippocampal neurons," Developmental Brain Research, vol. 107, no. 1, pp. 143-158, 1998.
[13] W. B. Pope, S. A. Enam, N. Bawa, B. E. Miller, H. A. Ghanbari, and W. L. Klein, "Phosphorylated tau epitope of Alzheimer's disease is coupled to axon development in the avian central nervous system," Experimental Neurology, vol. 120, no. 1, pp. 106-113, 1993.

[14] I. Cuchillo-Ibáñez, A. Seereeram, H. L. Byers et al., "Phosphorylation of tau regulates its axonal transport by controlling its binding to kinesin," The FASEB Journal, vol. 22, no. 9, pp. 3186-3195, 2008.

[15] E. Thies and E. M. Mandelkow, "Missorting of tau in neurons causes degeneration of synapses that can be rescued by the kinase MARK2/Par-1," Journal of Neuroscience, vol. 27, no. 11, pp. 2896-2907, 2007.

[16] G. A. Morfini, M. Burns, L. I. Binder et al., "Axonal transport defects in neurodegenerative diseases," Journal of Neuroscience, vol. 29, no. 41, pp. 12776-12786, 2009.

[17] L. M. Ittner, Y. D. Ke, F. Delerue et al., "Dendritic function of tau mediates amyloid-beta toxicity in Alzheimer's disease mouse models," Cell, vol. 142, no. 3, pp. 387-397, 2010.

[18] A. M. Pooler, A. Usardi, C. J. Evans, K. L. Philpott, W. Noble, and D. P. Hanger, "Dynamic association of tau with neuronal membranes is regulated by phosphorylation," Neurobiology of Aging. In press.

[19] A. M. Pooler and D. P. Hanger, "Functional implications of the association of tau with the plasma membrane," Biochemical Society Transactions, vol. 38, no. 4, pp. 1012$1015,2010$.

[20] C. H. Reynolds, C. J. Garwood, S. Wray et al., "Phosphorylation regulates tau interactions with Src homology 3 domains of phosphatidylinositol 3-kinase, phospholipase Cgamma1, Grb2, and Src family kinases," Journal of Biological Chemistry, vol. 283, no. 26, pp. 18177-18186, 2008.

[21] S. C. Hwang, D. Y. Jhon, Y. S. Bae, J. H. Kim, and S. G. Rhee, "Activation of phospholipase C-gamma by the concerted action of tau proteins and arachidonic acid," Journal of Biological Chemistry, vol. 271, no. 31, pp. 18342-18349, 1996.

[22] S. M. Jenkins and G. V. Johnson, "Tau complexes with phospholipase C-gamma in situ," NeuroReport, vol. 9, no. 1, pp. 67-71, 1998.

[23] P. A. Loomis, T. H. Howard, R. P. Castleberry, and L. I. Binder, "Identification of nuclear ç isoforms in human neuroblastoma cells," Proceedings of the National Academy of Sciences of the United States of America, vol. 87, no. 21, pp. 8422-8426, 1990.

[24] V. C. Thurston, R. P. Zinkowski, and L. I. Binder, "Tau as a nucleolar protein in human nonneural cells in vitro and in vivo," Chromosoma, vol. 105, no. 1, pp. 20-30, 1996.

[25] Y. Wang, P. A. Loomis, R. P. Zinkowski, and L. I. Binder, "A novel tau transcript in cultured human neuroblastoma cells expressing nuclear tau," Journal of Cell Biology, vol. 121, no. 2, pp. 257-267, 1993.

[26] D. C. Cross, J. P. Muñoz, P. Hernandez, and R. B. Maccioni, "Nuclear and cytoplasmic tau proteins from human nonneuronal cells share common structural and functional features with brain tau," Journal of Cellular Biochemistry, vol. 78, no. 2, pp. 305-317, 2000.

[27] M. K. Sjoberg, E. Shestakova, Z. Mansuroglu, R. B. Maccioni, and E. Bonnefoy, "Tau protein binds to pericentromeric DNA: a putative role for nuclear tau in nucleolar organization," Journal of Cell Science, vol. 119, no. 10, pp. 2025-2034, 2006.

[28] R. M. Brady, R. P. Zinkowski, and L. I. Binder, "Presence of tau in isolated nuclei from human brain," Neurobiology of Aging, vol. 16, no. 3, pp. 479-486, 1995. 
[29] A. Sultan, F. Nesslany, M. Violet et al., "Nuclear tau, a key player in neuronal DNA protection," Journal of Biological Chemistry, vol. 286, no. 6, pp. 4566-4575, 2011.

[30] J. A. Greenwood and G. V. W. Johnson, "Localization and in situ phosphorylation state of nuclear tau," Experimental Cell Research, vol. 220, no. 2, pp. 332-337, 1995.

[31] T. Kampers, P. Friedhoff, J. Biernat, E. M. Mandelkow, and E. Mandelkow, "RNA stimulates aggregation of microtubuleassociated protein tau into Alzheimer-like paired helical filaments," FEBS Letters, vol. 399, no. 3, pp. 344-349, 1996.

[32] W. Li, X. S. Wang, M. H. Qu, Y. Liu, and R. Q. He, "Human protein tau represses DNA replication in vitro," Biochimica et Biophysica Acta, vol. 1726, no. 3, pp. 280-286, 2005.

[33] S. W. Leung, L. H. Apponi, O. E. Cornejo et al., "Splice variants of the human $\mathrm{ZC} 3 \mathrm{H} 14$ gene generate multiple isoforms of a zinc finger polyadenosine RNA binding protein," Gene, vol. 439, no. 1-2, pp. 71-78, 2009.

[34] C. R. Guthrie, L. Greenup, J. B. Leverenz, and B. C. Kraemer, "MSUT2 is a determinant of susceptibility to tau neurotoxicity," Human Molecular Genetics, vol. 20, no. 10, pp. 1989-1999, 2011.

[35] C. R. Guthrie, G. D. Schellenberg, and B. C. Kraemer, "SUT2 potentiates tau-induced neurotoxicity in Caenorhabditis elegans," Human Molecular Genetics, vol. 18, no. 10, pp. 1825-1838, 2009.

[36] T. Lebouvier, T. M. Scales, R. Williamson et al., "The microtubule-associated protein tau is also phosphorylated on tyrosine," Journal of Alzheimer's Disease, vol. 18, no. 1, pp. 19, 2009.

[37] T. M. Scales, P. Derkinderen, K. Y. Leung et al., "Tyrosine phosphorylation of tau by the SRC family kinases lck and fyn," Molecular Neurodegeneration, vol. 6, p. 12, 2011.

[38] J. R. Woodgett, "Molecular cloning and expression of glycogen synthase kinase-3/factor A," The EMBO Journal, vol. 9, no. 8, pp. 2431-2438, 1990.

[39] D. P. Hanger, K. Hughes, J. R. Woodgett, J. P. Brion, and B. H. Anderton, "Glycogen synthase kinase-3 induces Alzheimer's disease-like phosphorylation of tau: generation of paired helical filament epitopes and neuronal localisation of the kinase," Neuroscience Letters, vol. 147, no. 1, pp. 58-62, 1992.

[40] A. Wood-Kaczmar, M. Kraus, K. Ishiguro, K. L. Philpott, and P. R. Gordon-Weeks, "An alternatively spliced form of glycogen synthase kinase-3beta is targeted to growing neurites and growth cones," Molecular and Cellular Neuroscience, vol. 42, no. 3, pp. 184-194, 2009.

[41] B. W. Doble, S. A. Patel, G. A. Wood, L. K. Kockeritz, and J. R. Woodgett, "Functional redundancy of GSK-3alpha and GSK3beta in Wnt/beta-catenin signaling shown by using an allelic series of embryonic stem cell lines," Developmental Cell, vol. 12, no. 6, pp. 957-971, 2007.

[42] L. T. Alon, S. Pietrokovski, S. Barkan et al., "Selective loss of glycogen synthase kinase-3alpha in birds reveals distinct roles for GSK-3 isozymes in tau phosphorylation," FEBS Letters, vol. 585, no. 8, pp. 1158-1162, 2011.

[43] K. MacAulay, B. W. Doble, S. A. Patel et al., "Glycogen synthase kinase 3alpha-specific regulation of murine hepatic glycogen metabolism," Cell Metabolism, vol. 6, no. 4, pp. 329337, 2007.

[44] K. P. Hoeflich, J. Luo, E. A. Rubie, M. S. Tsao, O. Jin, and J. R. Woodgett, "Requirement for glycogen synthase kinase-3beta in cell survival and NF-kappaB activation," Nature, vol. 406, no. 6791, pp. 86-90, 2000.
[45] J. E. Forde and T. C. Dale, "Glycogen synthase kinase 3: a key regulator of cellular fate," Cellular and Molecular Life Sciences, vol. 64, no. 15, pp. 1930-1944, 2007.

[46] S. Frame and P. Cohen, "GSK3 takes centre stage more than 20 years after its discovery," Biochemical Journal, vol. 359, no. 1, pp. 1-16, 2001.

[47] F. Hernández, E. Langa, R. Cuadros, J. Avila, and N. Villanueva, "Regulation of GSK3 isoforms by phosphatases PP1 and PP2A," Molecular and Cellular Biochemistry, vol. 344, no. 1-2, pp. 211-215, 2010.

[48] W. Qian, J. Shi, X. Yin et al., "PP2A regulates tau phosphorylation directly and also indirectly via activating GSK-3beta," Journal of Alzheimer's Disease, vol. 19, no. 4, pp. 1221-1229, 2010.

[49] Y. Kim, Y. I. Lee, M. Seo et al., "Calcineurin dephosphorylates glycogen synthase kinase- 3 beta at serine- 9 in neuroblastderived cells," Journal of Neurochemistry, vol. 111, no. 2, pp. 344-354, 2009.

[50] P. Cohen, "The structure and regulation of protein phosphatases," Annual Review of Biochemistry, vol. 58, pp. 453508, 1989.

[51] I. D’Souza and G. D. Schellenberg, “Determinants of 4repeat tau expression. Coordination between enhancing and inhibitory splicing sequences for exon 10 inclusion," Journal of Biological Chemistry, vol. 275, no. 23, pp. 17700-17709, 2000.

[52] F. Hernández, M. Perez, J. J. Lucas, A. M. Mata, R. Bhat, and J. Avila, "Glycogen synthase kinase-3 plays a crucial role in tau exon 10 splicing and intranuclear distribution of SC35. Implications for Alzheimer's disease," Journal of Biological Chemistry, vol. 279, no. 5, pp. 3801-3806, 2004.

[53] A. Takashima, T. Honda, K. Yasutake et al., "Activation of tau protein kinase I/glycogen synthase kinase-3beta by amyloid beta peptide (25-35) enhances phosphorylation of tau in hippocampal neurons," Neuroscience Research, vol. 31, no. 4, pp. 317-323, 1998.

[54] K. L. Chen, R. Y. Yuan, C. J. Hu, and C. Y. Hsu, "Amyloid-beta peptide alteration of tau exon-10 splicing via the GSK3betaSC35 pathway," Neurobiology of Disease, vol. 40, no. 2, pp. 378-385, 2010.

[55] K. Ishiguro, M. Takahashi, K. Tomizawa et al., “Tau protein kinase I converts normal tau protein into A68- like component of paired helical filaments," Journal of Biological Chemistry, vol. 267, no. 15, pp. 10897-10901, 1992.

[56] S. Lovestone, C. H. Reynolds, D. Latimer et al., "Alzheimer's disease-like phosphorylation of the microtubule-associated protein tau by glycogen synthase kinase-3 in transfected mammalian cells," Current Biology, vol. 4, no. 12, pp. 10771086, 1994.

[57] R. Gómez-Sintes, F. Hernández, A. Bortolozzi et al., "Neuronal apoptosis and reversible motor deficit in dominantnegative GSK-3 conditional transgenic mice," The EMBO Journal, vol. 26, no. 11, pp. 2743-2754, 2007.

[58] Z. Yuan, A. Agarwal-Mawal, and H. K. Paudel, "14-3-3 binds to and mediates phosphorylation of microtubule-associated tau protein by Ser9-phosphorylated glycogen synthase kinase 3beta in the brain," Journal of Biological Chemistry, vol. 279, no. 25, pp. 26105-26114, 2004.

[59] A. Agarwal-Mawal, H. Y. Qureshi, P. W. Cafferty et al., "143-3 connects glycogen synthase kinase-3 beta to tau within a brain microtubule-associated tau phosphorylation complex," Journal of Biological Chemistry, vol. 278, no. 15, pp. 1272212728, 2003. 
[60] D. P. Hanger, H. L. Byers, S. Wray et al., "Novel phosphorylation sites in tau from Alzheimer brain support a role for casein kinase 1 in disease pathogenesis," Journal of Biological Chemistry, vol. 282, no. 32, pp. 23645-23654, 2007.

[61] C. H. Reynolds, J. C. Betts, W. P. Blackstock, A. R. Nebreda, and B. H. Anderton, "Phosphorylation sites on tau identified by nanoelectrospray mass spectrometry: differences in vitro between the mitogen-activated protein kinases ERK2, c-Jun $\mathrm{N}$-terminal kinase and P38, and glycogen synthase kinase3beta," Journal of Neurochemistry, vol. 74, no. 4, pp. 15871595, 2000.

[62] M. A. Utton, A. Vandecandelaere, U. Wagner et al., "Phosphorylation of tau by glycogen synthase kinase 3beta affects the ability of tau to promote microtubule self-assembly," Biochemical Journal, vol. 323, no. 3, pp. 741-747, 1997.

[63] G. Li, H. Yin, and J. Kuret, "Casein kinase 1 delta phosphorylates tau and disrupts its binding to microtubules," Journal of Biological Chemistry, vol. 279, no. 16, pp. 15938-15945, 2004.

[64] G. A. Morfini, G. Szebenyi, R. G. Elluru, N. Ratner, and S. T. Brady, "Glycogen synthase kinase 3 phosphorylates kinesin light chains and negatively regulates kinesin-based motility," The EMBO Journal, vol. 21, no. 3, pp. 281-293, 2002.

[65] P. J. Kennelly and E. G. Krebs, "Consensus sequences as substrate specificity determinants for protein kinases and protein phosphatases," Journal of Biological Chemistry, vol. 266, no. 24, pp. 15555-15558, 1991.

[66] A. R. Cole, F. Causeret, G. Yadirgi et al., "Distinct priming kinases contribute to differential regulation of collapsin response mediator proteins by glycogen synthase kinase- 3 in vivo," Journal of Biological Chemistry, vol. 281, no. 24, pp. 16591-16598, 2006.

[67] A. Leroy, I. Landrieu, I. Huvent et al., "Spectroscopic studies of GSK3beta phosphorylation of the neuronal tau protein and its interaction with the $\mathrm{N}$-terminal domain of apolipoprotein E," Journal of Biological Chemistry, vol. 285, no. 43, pp. 33435-33444, 2010.

[68] F. Zhang, C. J. Phiel, L. Spece, N. Gurvich, and P. S. Klein, "Inhibitory phosphorylation of glycogen synthase kinase-3 (GSK-3) in response to lithium. Evidence for autoregulation of GSK-3," Journal of Biological Chemistry, vol. 278, no. 35, pp. 33067-33077, 2003.

[69] P. Polakis, "Casein kinase 1: a Wnt'er of disconnect," Current Biology, vol. 12, no. 14, pp. R499-R501, 2002.

[70] T. J. Singh, N. Haque, I. Grundke-Iqbal, and K. Iqbal, "Rapid Alzheimer-like phosphorylation of tau by the synergistic actions of non-proline-dependent protein kinases and GSK3," FEBS Letters, vol. 358, no. 3, pp. 267-272, 1995.

[71] J. H. Cho and G. V. Johnson, "Glycogen synthase kinase 3beta phosphorylates tau at both primed and unprimed sites. Differential impact on microtubule binding," Journal of Biological Chemistry, vol. 278, no. 1, pp. 187-193, 2003.

[72] T. Li, C. A. Hawkes, H. Y. Qureshi, S. Kar, and H. K. Paudel, "Cyclin-dependent protein kinase 5 primes microtubuleassociated protein tau site-specifically for glycogen synthase kinase 3beta," Biochemistry, vol. 45, no. 10, pp. 3134-3145, 2006.

[73] J. Z. Wang, Q. Wu, A. Smith, I. Grundke-Iqbal, and K. Iqbal, "Tau is phosphorylated by GSK-3 at several sites found in Alzheimer disease and its biological activity markedly inhibited only after it is prephosphorylated by A-kinase," FEBS Letters, vol. 436, no. 1, pp. 28-34, 1998.

[74] M. P. M. Soutar, W. Y. Kim, R. Williamson et al., "Evidence that glycogen synthase kinase-3 isoforms have distinct substrate preference in the brain," Journal of Neurochemistry, vol. 115, no. 4, pp. 974-983, 2010.

[75] F. Mukai, K. Ishiguro, Y. Sano, and S. C. Fujita, "Aternative splicing isoform of tau protein kinase I/glycogen synthase kinase 3beta," Journal of Neurochemistry, vol. 81, no. 5, pp. 1073-1083, 2002.

[76] K. Saeki, M. Machida, Y. Kinoshita, R. Takasawa, and S. Tanuma, "Glycogen synthase kinase-3beta2 has lower phosphorylation activity to tau than glycogen synthase kinase3betal," Biological and Pharmaceutical Bulletin, vol. 34, no. 1, pp. 146-149, 2011.

[77] Z. Castaño, P. R. Gordon-Weeks, and R. M. Kypta, "The neuron-specific isoform of glycogen synthase kinase-3beta is required for axon growth," Journal of Neurochemistry, vol. 113, no. 1, pp. 117-130, 2010.

[78] S. G. Greenberg and P. Davies, "A preparation of Alzheimer paired helical filaments that displays distinct tau proteins by polyacrylamide gel electrophoresis," Proceedings of the National Academy of Sciences of the United States of America, vol. 87, no. 15, pp. 5827-5831, 1990.

[79] M. Hasegawa, M. Morishima-Kawashima, K. Takio, M. Suzuki, K. Titani, and Y. Ihara, "Protein sequence and mass spectrometric analyses of tau in the Alzheimer's disease brain," Journal of Biological Chemistry, vol. 267, no. 24, pp. 17047-17054, 1992.

[80] M. Morishima-Kawashima, M. Hasegawa, K. Takio et al., "Proline-directed and non-proline-directed phosphorylation of PHF-tau," Journal of Biological Chemistry, vol. 270, no. 2, pp. 823-829, 1995.

[81] D. P. Hanger, J. C. Betts, T. L. Loviny, W. P. Blackstock, and B. H. Anderton, "New phosphorylation sites identified in hyperphosphorylated tau (paired helical filament-tau) from Alzheimer's disease brain using nanoelectrospray mass spectrometry," Journal of Neurochemistry, vol. 71, no. 6, pp. 2465-2476, 1998.

[82] M. Morishima-Kawashima, M. Hasegawa, K. Takio et al., "Hyperphosphorylation of tau in PHF," Neurobiology of Aging, vol. 16, no. 3, pp. 365-371, 1995.

[83] S. Wray, M. Saxton, B. H. Anderton, and D. P. Hanger, "Direct analysis of tau from PSP brain identifies new phosphorylation sites and a major fragment of N-terminally cleaved tau containing four microtubule-binding repeats," Journal of Neurochemistry, vol. 105, no. 6, pp. 2343-2352, 2008.

[84] J. J. Pei, E. Braak, H. Braak et al., "Distribution of active glycogen synthase kinase 3beta (GSK-3beta) in brains staged for Alzheimer disease neurofibrillary changes," Journal of Neuropathology and Experimental Neurology, vol. 58, no. 9, pp. 1010-1019, 1999.

[85] I. Ferrer, M. D. Barrachina, and B. Puig, "Glycogen synthase kinase-3 is associated with neuronal and glial hyperphosphorylated tau deposits in Alzheimer's diasese, Pick's disease, progressive supranuclear palsy and corticobasal degeneration," Acta Neuropathologica, vol. 104, no. 6, pp. 583-591, 2002.

[86] S. D. Harr, R. D. Hollister, and B. T. Hyman, "Glycogen synthase kinase 3 alpha and 3 beta do not colocalize with neurofibrillary tangles," Neurobiology of Aging, vol. 17, no. 3, pp. 343-348, 1996.

[87] U. Wagner, M. A. Utton, J. M. Gallo, and C. C. Miller, "Cellular phosphorylation of tau by GSK-3beta influences tau binding to microtubules and microtubule organisation," Journal of Cell Science, vol. 109, no. 6, pp. 1537-1543, 1996. 
[88] H. Sang, Z. Lu, Y. Li, B. G. Ru, W. Wang, and J. Chen, "Phosphorylation of tau by glycogen synthase kinase 3beta in intact mammalian cells influences the stability of microtubules," Neuroscience Letters, vol. 312, no. 3, pp. 141-144, 2001.

[89] U. Wagner, J. Brownlees, N. G. Irving, F. R. Lucas, P. C. Salinas, and C. C. Miller, "Overexpression of the mouse dishevelled-1 protein inhibits GSK-3beta-mediated phosphorylation of tau in transfected mammalian cells," FEBS Letters, vol. 411, no. 2-3, pp. 369-372, 1997.

[90] M. Hong, D. C. Chen, P. S. Klein, and V. M. Lee, "Lithium reduces tau phosphorylation by inhibition of glycogen synthase kinase-3," Journal of Biological Chemistry, vol. 272, no. 40, pp. 25326-25332, 1997.

[91] C. J. Phiel and P. S. Klein, "Molecular targets of lithium action," Annual Review of Pharmacology and Toxicology, vol. 41, pp. 789-813, 2001.

[92] D. A. Cross, A. A. Culbert, K. A. Chalmers, L. Facci, S. D. Skaper, and A. D. Reith, "Selective small-molecule inhibitors of glycogen synthase kinase-3 activity protect primary neurones from death," Journal of Neurochemistry, vol. 77, no. 1, pp. 94-102, 2001.

[93] Q. H. Ye, G. Xu, D. Lv, Z. Cheng, J. S. Li, and Y. Hu, "Synthesis and biological evaluation of novel 4-azaindolylindolyl-maleimides as glycogen synthase kinase-3beta (GSK3beta) inhibitors," Bioorganic and Medicinal Chemistry, vol. 17, no. 13, pp. 4302-4312, 2009.

[94] M. Takahashi, K. Yasutake, and K. Tomizawa, "Lithium inhibits neurite growth and tau protein kinase I/glycogen synthase kinase-3beta-dependent phosphorylation of juvenile tau in cultured hippocampal neurons," Journal of Neurochemistry, vol. 73, no. 5, pp. 2073-2083, 1999.

[95] N. E. LaPointe, G. A. Morfini, G. Pigino et al., "The amino terminus of tau inhibits kinesin-dependent axonal transport: implications for filament toxicity," Journal of Neuroscience Research, vol. 87, no. 2, pp. 440-451, 2009.

[96] G. R. Jackson, M. Wiedau-Pazos, T. K. Sang et al., "Human wild-type tau interacts with wingless pathway components and produces neurofibrillary pathology in Drosophila," Neuron, vol. 34, no. 4, pp. 509-519, 2002.

[97] I. Nishimura, Y. Yang, and B. Lu, "PAR-1 kinase plays an initiator role in a temporally ordered phosphorylation process that confers tau toxicity in Drosophila," Cell, vol. 116, no. 5, pp. 671-682, 2004.

[98] S. Chatterjee, T. K. Sang, G. M. Lawless, and G. R. Jackson, "Dissociation of tau toxicity and phosphorylation: role of GSK-3beta, MARK and Cdk5 in a Drosophila model," Human Molecular Genetics, vol. 18, no. 1, pp. 164-177, 2009.

[99] J. M. Shulman and M. B. Feany, "Genetic modifiers of tauopathy in Drosophila," Genetics, vol. 165, no. 3, pp. 12331242, 2003.

[100] X. Chen, Y. Li, J. Huang et al., "Study of tauopathies by comparing Drosophila and human tau in Drosophila," Cell and Tissue Research, vol. 329, no. 1, pp. 169-178, 2007.

[101] G. Drewes, A. Ebneth, U. Preuss, E. M. Mandelkow, and E. Mandelkow, "MARK, a novel family of protein kinases that phosphorylate microtubule- associated proteins and trigger microtubule disruption," Cell, vol. 89, no. 2, pp. 297-308, 1997.

[102] E. M. Mandelkow, E. Thies, B. Trinczek, J. Biernat, and E. Mandelkow, "MARK/PAR1 kinase is a regulator of microtubule-dependent transport in axons," Journal of Cell Biology, vol. 167, no. 1, pp. 99-110, 2004.
[103] T. Timm, K. Balusamy, X. Li, J. Biernat, E. Mandelkow, and E. M. Mandelkow, "Glycogen Synthase Kinase (GSK) 3beta directly phosphorylates serine 212 in the regulatory loop and inhibits microtubule affinity-regulating kinase (MARK) 2," Journal of Biological Chemistry, vol. 283, no. 27, pp. 1887318882, 2008.

[104] G. Heidary and M. E. Fortini, "Identification and characterization of the Drosophila tau homolog," Mechanisms of Development, vol. 108, no. 1-2, pp. 171-178, 2001.

[105] W. Noble, D. P. Hanger, and J. M. Gallo, "Transgenic mouse models of tauopathy in drug discovery," CNS and Neurological Disorders—Drug Targets, vol. 9, no. 4, pp. 403428, 2010.

[106] J. J. Lucas, F. Hernandez, P. Gomez-Ramos, M. A. Moran, R. Hen, and J. Avila, "Decreased nuclear ss-catenin, tau hyperphosphorylation and neurodegeneration in GSK-3ss conditional transgenic mice," The EMBO Journal, vol. 20, no. 1-2, pp. 27-39, 2001.

[107] F. Hernández, J. I. Borrell, C. Guaza, J. Avila, and J. J. Lucas, "Spatial learning deficit in transgenic mice that conditionally over-express GSK-3beta in the brain but do not form tau filaments," Journal of Neurochemistry, vol. 83, no. 6, pp. 15291533, 2002.

[108] T. Engel, F. Hernández, J. Avila, and J. J. Lucas, "Full reversal of Alzheimer's disease-like phenotype in a mouse model with conditional overexpression of glycogen synthase kinase-3," Journal of Neuroscience, vol. 26, no. 19, pp. 5083-5090, 2006.

[109] K. Spittaels, C. Van den Haute, J. Van Dorpe et al., "Glycogen synthase kinase-3beta phosphorylates protein tau and rescues the axonopathy in the central nervous system of human four-repeat tau transgenic mice," Journal of Biological Chemistry, vol. 275, no. 52, pp. 41340-41349, 2000.

[110] M. Perez, A. I. Rojo, F. Wandosell, J. Diaz-Nido, and J. Avila, "Prion peptide induces neuronal cell death through a pathway involving glycogen synthase kinase 3," Biochemical Journal, vol. 372, no. 1, pp. 129-136, 2003.

[111] W. Noble, E. Planel, C. Zehr et al., "Inhibition of glycogen synthase kinase- 3 by lithium correlates with reduced tauopathy and degeneration in vivo," Proceedings of the National Academy of Sciences of the United States of America, vol. 102, no. 19, pp. 6990-6995, 2005.

[112] H. Nakashima, T. Ishihara, P. Suguimoto et al., "Chronic lithium treatment decreases tau lesions by promoting ubiquitination in a mouse model of tauopathies," Acta Neuropathologica, vol. 110, no. 6, pp. 547-556, 2005.

[113] L. Sereno, M. Coma, M. Rodriguez et al., "A novel GSK3beta inhibitor reduces Alzheimer's pathology and rescues neuronal loss in vivo," Neurobiology of Disease, vol. 35, no. 3, pp. 359-367, 2009.

[114] K. Leroy, K. Ando, C. Héraud et al., "Lithium treatment arrests the development of neurofibrillary tangles in mutant tau transgenic mice with advanced neurofibrillary pathology," Journal of Alzheimer's Disease, vol. 19, no. 2, pp. 705719, 2010. 


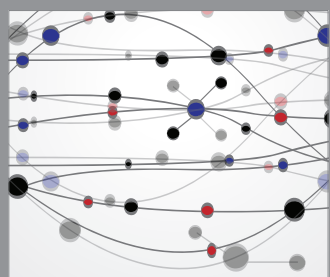

The Scientific World Journal
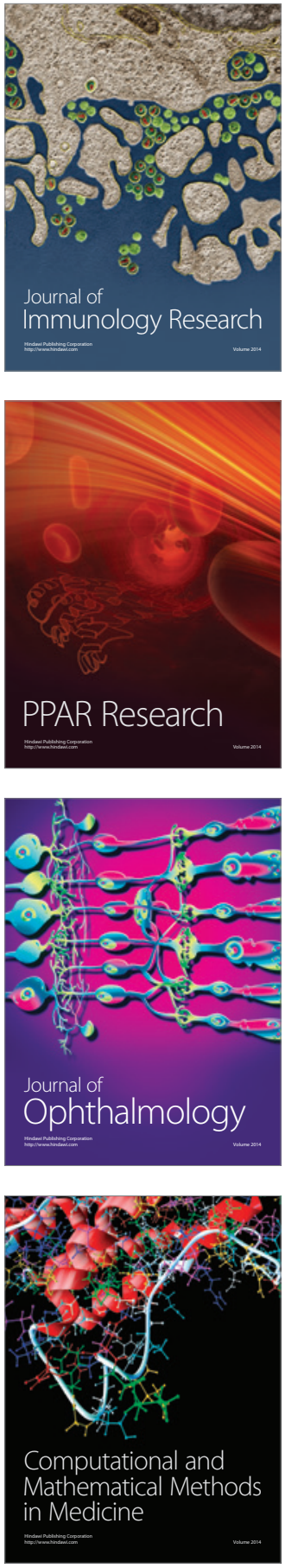

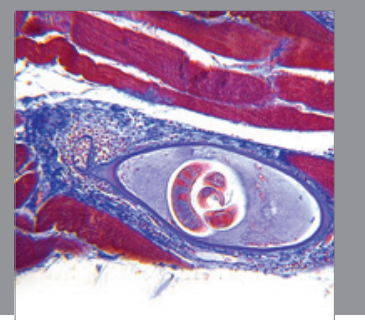

Gastroenterology

Research and Practice
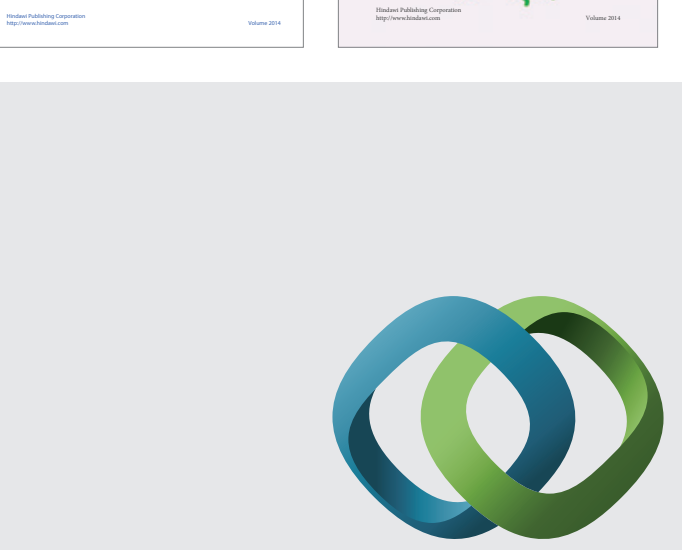

\section{Hindawi}

Submit your manuscripts at

http://www.hindawi.com
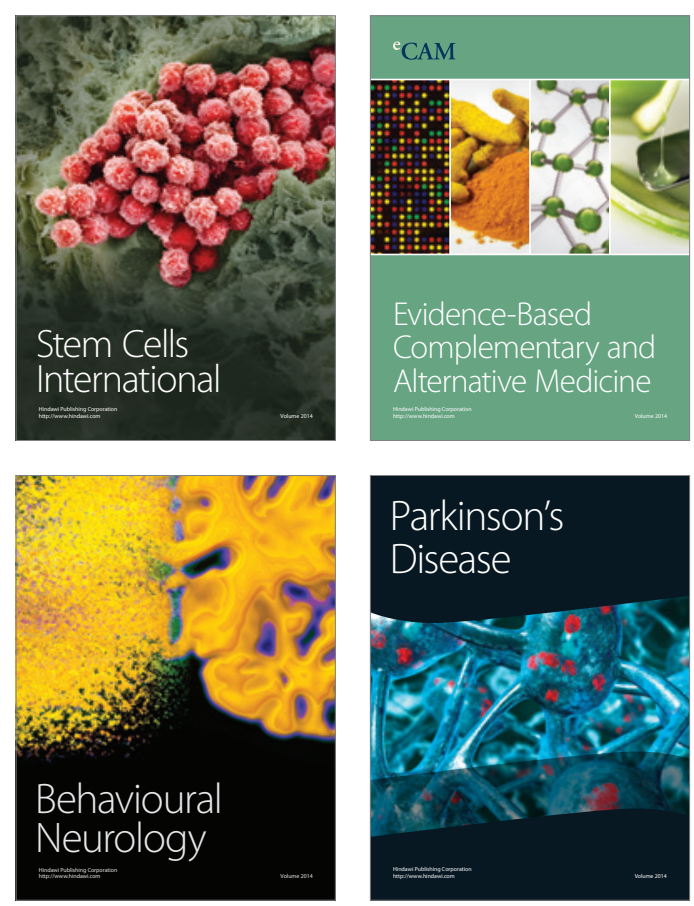

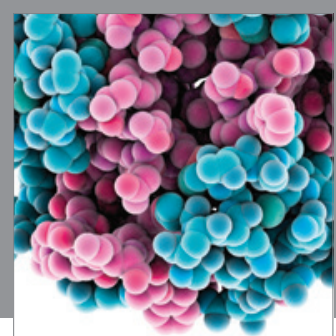

Journal of
Diabetes Research

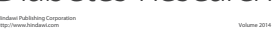

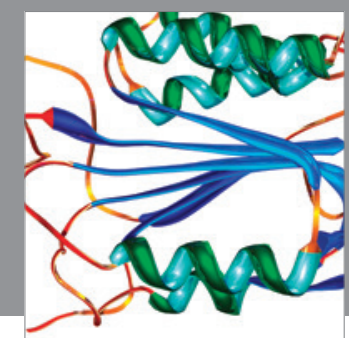

Disease Markers
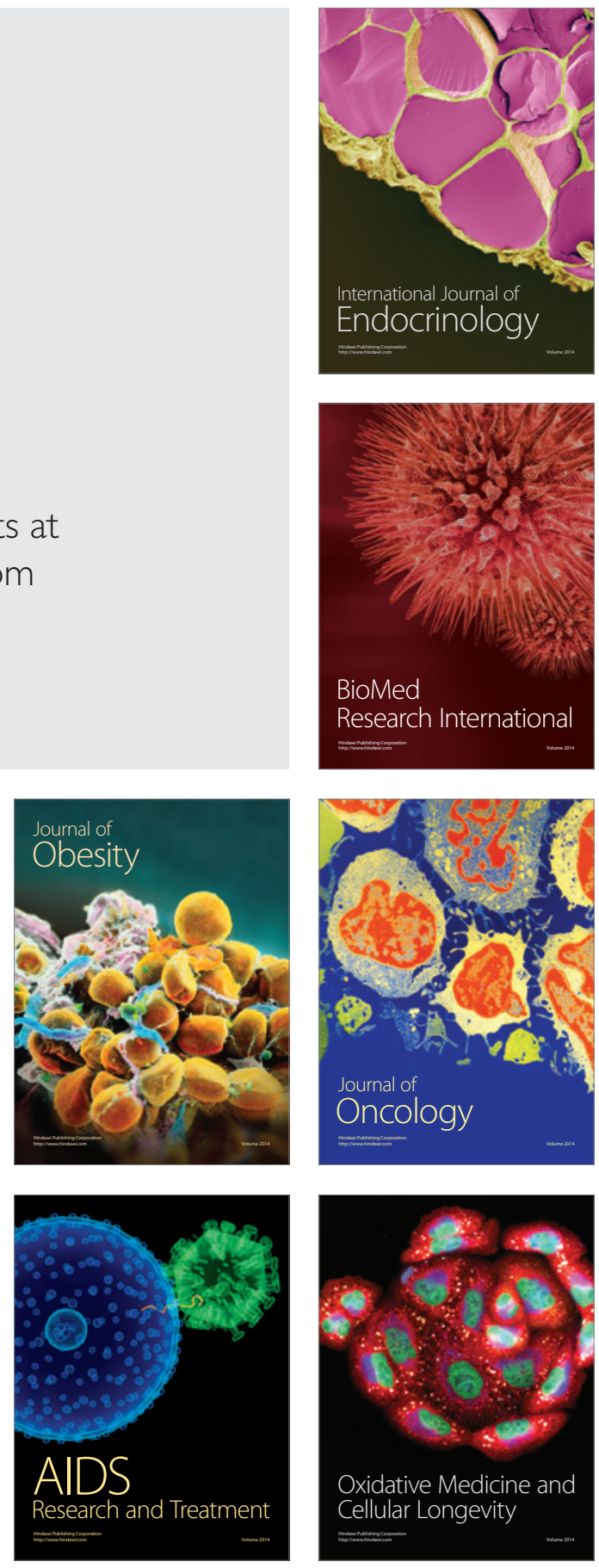